\title{
Paideusis
}

\section{Decentering the Ego-self and Releasing the Care-consciousness}

\section{Heesoon Bai}

Volume 12, Number 2, 1999

URI: https://id.erudit.org/iderudit/1073086ar

DOI: https://doi.org/10.7202/1073086ar

See table of contents

Publisher(s)

Canadian Philosophy of Education Society

ISSN

0838-4517 (print)

1916-0348 (digital)

Explore this journal

Cite this article

Bai, H. (1999). Decentering the Ego-self and Releasing the Care-consciousness.

Paideusis, 12(2), 5-18. https://doi.org/10.7202/1073086ar 


\title{
Decentering the Ego-self and Releasing the Care-consciousness
}

\author{
Heesoon Bai, Simon Fraser University
}

Yun Yen asked Tao Wu, "What does the Bodhisattva of Great Compassion use so many hands and eyes for?"

Wu said, "It's like someone reaching back grasping for a pillow in the middle of the night."

Yen said, "I understand."

Wu said, "How do you understand it?"

Yen said, "All over the body are hands and eyes."

The Blue Cliff Record

\section{Introduction}

On the eve of the new millennium, we face a world whose "carrying capacity"1 is, by all accounts, dangerously out of balance with even the basic requirements for the planet's population of six billion people. ${ }^{2}$

The human population as a whole, but especially in the industrialized countries, has been rapidly diminishing the earth's carrying capacity. With the prospect of adding another four billion in the next fifty years, our utmost challenge is to expand our caring capacity radically so as not only to cope with the ever serious consequences of social inequities and ecological damage but also to restore the earth's overall carrying capacity. ${ }^{3}$ Since caring is a moral capacity, the challenge of expanding caring properly belongs to the task of moral education. This paper explores ways of cultivating an extraordinarily expansive caring consciousness for an extraordinarily challenging time such as ours.

This is not the first time humans have faced the challenge of caring. But now the scope and urgency of the challenge have changed. Morality has always been centrally about extending care-consciousness beyond the narrow confines of the individual self to the other, be it the family, clan, village, or nation. We are now challenged to extend care-consciousness to the whole of the biosphere and to the whole of humanity as a constituent part of it. ${ }^{4}$ Also, unlike before, we do not have the luxury of evading this challenge for the same reason that we could not afford to let a critically wounded person lose more blood. In both cases, intensive care is a must.

My argument proceeds in two stages: first, $I$ analyze the conditions that afford caring, and then I examine one "experiment" in caring consciousness, that of the Buddhist theory and practice of caring. I select this example because it illustrates clearly the conditions of care-consciousness that $I$ analyze in the first part of the paper.

\section{The conditions of caring}

Caring and other cognate moral dispositions are said to be "otherregarding" virtues (Blum, 1994). In other words, caring occurs when the self directs its good-willed attention to the other. The objective of caring is the well-being of the other. However, just as water naturally flows toward the sea, caring naturally flows toward those to whom we have close ties. The closer the relatedness is, the more naturally and abundantly caring flows. 
The strongly bonded parent and child would be a paradigm of such close relatedness. Thus, though caring is an other-regarding virtue, here "otherness" has to be understood in terms of the degree of self-other relatedness. For this reason, I argue that natural caring ends at the boundary of the self-other relationship. ${ }^{5}$ That is, when the other lies outside the parameters of self-other relatedness, the other is a foreign entity, an alien. Given this, the self's attitude towards the other may not be just indifference but often active discomfort and even fear. Xenophobia ${ }^{6}$ is one of the oldest fears of humanity. It does not just paralyze the afflicted into indifference and inaction. In the attempt to overcome the discomfort and fear, the afflicted may set out to destroy the alien object.

But why should otherness cause such discomfort and fear? I suggest, without elaborating here, ${ }^{7}$ that the answer may lie in the phenomenon of selfawareness itself. Insofar as the self is aware of itself as a substantively separate and distinct individual entity, all others are excluded from the self. What the other is, the self is not, and vice versa. And insofar as the self's overwhelming interest is its own survival, the other poses real or potential threat. As long as the self perceives the other as a source of potential or real threat to itself, its response comes roughly in three kinds: avoid the other; "thingify" it and turn it into one's resource and instrument; or, going a step further, simply annihilate it. None of these moves entertains the possibility of the self considering the other symmetrically; first, considering the other as being a self to itself and, second, considering how this self may also appear as an other to that self, just as that self appears as an other to this self. However, if such perception of symmetry does occur, then it can be the basis for a mutual or reciprocal relationship between the self and the other. Contractarian relationship is the result.

However, in real world situations, the contractarian relationship is difficult to achieve and maintain for it requires that all participants be equal consociates, ${ }^{8}$ capable of reciprocating perceptions of each other that are mutually recognized to be valid. Spelled out this way, we should realize that the vast majority of others in the world, both in the human and non-human domains, are functionally excluded from the possibilities of contractarian relationships with each other. For example, we surely cannot expect animals to enter into a contractarian relationship with humans. Nor is the prospect of such a relationship guaranteed amongst humans. Hence, if our moral objective is the self-other relatedness that encompasses the whole of humanity and beyond, the contractarian response, although more viable than the previously mentioned other three responses, is still of limited utility.

It seems to me that the contractarian response is a limit case of self-other relatedness in the sense that it is the maximal relatedness that we can hope to achieve, given the initial understanding that the self is substantively and categorically separate from the other. But the givenness of this initial understanding is not immune to challenge. I would propose that the self is not substantively separate from the other and, therefore, is inherently open to, and is completed in, the other. In other words, the self is always already partially constituted by the other. As such, the self is never identical to itself ${ }^{9}$ insofar as it co-emerges moment by moment with the whole shifting field of otherness that the self encounters. In this sense, then, the self is continuous with the other. ${ }^{10}$ The self dynamically flows into, out of, and with the other, creatively assuming a complex, polymorphous sense of agency. It is not the simple sense of agency 
wherein the subject (the self) does something to its object (the other). Returning to my earlier remark about the natural flow of caring in the self-other relatedness, I now claim that moral caring as a flow of attention, concern, love, and compassion would be generously afforded in the fluid dynamics of the self-other continuity. Conversely, the flow of moral caring would naturally be checked or even blocked in the self that perceives itself as categorically separate from the other.

\section{Caring as the foundation of morality}

Caring resulting from the self-other continuity is foundational to morality in the eudaimonic view of morality that aims at mutual harmony and flourishing amongst all beings whose existence is perceived to be interdependent and coemergent. Seen this way, the domain of morality is not restricted to human relationship but encompasses the whole of the ecosystem and beyond. 11 The effort of moral education in this non-anthropocentric framework may be seen as a progressive widening of the circle of bonding or integration, starting with the self's integration with the family, community, and so on, and gradually reaching out to the biosphere and beyond. This model of widening of the moral horizon echoes the Confucian notion of self-cultivation ( $\mathrm{Tu}, 1994)$. In broadly comparing the latter model of moral education to the prevailing model in the West, ${ }^{12}$ a significant difference will be noticed. Namely, the hallmark of moral development and achievement is not autonomy (literally, self-governing) but "ontonomy," (literally, reality-governing) to use Panikkar's neologism. By "ontonomy," I understand the realization of the intrinsic interconnectedness of all beings (Panikkar, 1992). Thich Nhat Hanh's equivalent terminology is "interbeing." These notions refer to the realization that the self is inseparable from all other beings and, hence, that moral caring is not really about building up the sovereign autonomous self who can then bestow caring upon other beings and situations deemed to be worthy of respect according to some rational calculus. Rather, it is about empathy and compassion born of the perception that there is no such thing as an autonomous self and that the self and the other make up one unity of continuous Being.

The autonomy-based moral paradigm cannot but epistemically and psychologically privilege the self. For this reason, even in the best effort of directing caring outwardly to the other, it is easily caught up in the dilemma and calculus of self-interest versus other-interest. Enlightened self-interest as a moral stance, widely endorsed at present, is a predictable result. As well, altruism that subsumes the self-interest under the other-interest is the other, opposite result. Both of these moral orientations share the same origin in a self-other dichotomy. However, in the ontonomy-based moral paradigm that I am advocating, since the self and the other together form an ontological unit, the self as a constituent part can no more be privileged than the other. Let me illustrate this point with a couple of examples.

To be a truly moral person in the ontonomic sense, it is not enough that $I$ help my friend in distress by offering my time and energy to look after her baby when she is unable to pay for baby-sitting but has to go out to meet her appointment. If I perform this good Samaritan's deed out of a sense of moral duty, grudgingly and with resentment, I am less than fully moral, although I probably am more moral than if I did not help at all. Similarly, if my deciding to help her 
has been motivated by a prudential or self-seeking consideration involved in calculating some kind of retum benefit for me in the future, this, too, is not perfectly moral. As well, if I helped my friend because not to do so would have made me feel bad in having failed to meet my moral standard or because knowing that I have done good deeds would give me a deep sense of satisfaction and pride, these, too, would be less than fully moral. We are less than fully moral so long as the motivation to perform moral actions stems from considering one's interest or welfare over and above others'. To make the same point but in reverse, to be fully moral is to place the welfare of others on equal footing as one's own, realizing that the self and the other are inherently coincidental or extensive. We may call this idea the moral principle of equality and impartiality, and, as I derived it, it is based on moral ontonomy discussed earlier.

However, this principle is not to be mistaken as an understanding that, therefore, one should not invest more time and attention in oneself than in another. Indeed, I think we can show that it is in general a more efficient way of overall ontonomical caring to have each person first look after himself or herself as far as possible and only second look after, or be looked after by, others. Can we imagine, for a simple example, how inefficient it would be to always rely on having others tie one's own shoe laces? But this strategy of tying one's own shoe laces does not conflict with the moral principle of equality and impartiality. The reason why I tie my own laces as long as I am able to is not because I take greater interest in my own well-being than in others'. By the same token, the principle of equality and impartiality does not require one to place the interest of others' well-being over and above one's own. But, again, in order to most skillfully observe this principle, one might have to pay more attention to another's shoe laces than one's own. I can afford to go around with loose shoe laces without too great a risk of tripping and breaking my bones, but given the state of my octogenarian mother's extreme osteoporosis and the consequent risk of injury, I pay far greater attention to her shoe laces than mine, and this is not because I consider her well-being greater than mine. In fact, in the self-other continuity model that I have advanced, separating my well-being from my mother's makes little sense.

Let me try another example. Suppose that I witness a fire. I see a stranger engulfed in flame. What do I do as a moral person? If my sense of morality is that of enlightened self-interest, my first moral impulse would not be to rush into the fire and drag out the victim. After all, it is the stranger and not me who is burning. If I decide to risk myself to rescue the victim, it has to be for a reason strong enough to override my sense of risk to my person, even if the reason is my moral heroism or the dreadful thought of guilt for not rescuing the victim.

Or, if my sense of morality is disciplined by Kantian deontology, I might be dragging myself, literally, to the stranger in flame out of moral duty, while I fight my own disinclination and my wish to run away. Other moral paradigms would discipline our sense of morality differently, but I shall not undertake the exercise of comparison here but instead focus on the moral paradigm of ontonomy. If my moral sense has been disciplined by the latter, my impulse would be simply to rush in to drag out the burning victim, just as I would simply pull out my own leg when caught in a fire. The moral motivation for these two actions would be exactly the same-to end suffering. It does not matter to my moral impulse whether the suffering is located in my body or in someone else's, 
for "I" am connected by empathy and compassion to both locations or bodies. However, between impulse and action, the practical intelligence that calculates the optimal moral performance is interposed. Thus, though my impulse is to simply rush into the flame, my practical intelligence may inform me that there is no way I can drag out the victim, given that he must weigh two or three times my weight. In the worst scenario, there may be absolutely nothing I can do to save the victim or lessen his suffering. I just might have to suffer the agony of witnessing the victim painfully burning to death, just as I would suffer the pain of my leg or the rest of my body burning, if I were not in any position to move my body. This is not an example of the break-down of caring but of the material constraints that caring always faces in expressing itself.

\section{Obstacles to moral caring}

Our culture stresses autonomy and consequent individual excellence and achievement. Successful people are those who stand, or stand out, over and above others. Hegemony is the name of the social game for both persons and nations. Global competition is not just a slogan in the economic-financial field; it has so deeply entered education tath it has become one of the main educational goals for our schools. Now, to be fair, I must acknowledge that co-operation, too, figures in this game. But it is no less egocentric. We co-operate so as to gain individual advantage. ${ }^{13}$ But co-operation as such cannot be the basis for the kind of morality based on ontonomy that I have sketched here. How then do we realize and enact an ontonomy-based morality? In keeping with my earlier claim that the realization of ontonomy results in compassion and empathy, this time, I argue the converse-namely, that through the exercise of empathy and compassion, we realize the continuity of the self with the other. In a moment of empathic perception where the presence of the other has affected one to the point of bringing about a whole chain of bodily responses, one may realize, if one thinks about it carefully, how much the other has become part of the self in the literal sense. ${ }^{14}$ For example, the perfume of the flower in the room enters my body and psyche and become part of me and, thus, who I am this moment is a transfusion of me and the flower, however transient and limited such transfusion may be at times.

Yet, the possibility of realizing such transfusion seems to be regularly aborted by the grammar of our language. ${ }^{15}$ The usual description, "I smell the rose," says nothing about the transfusion between the subject and the object but only their mechanical atomistic interaction that leaves all three ontological terms-the subject, object, and event of interaction-substantively intact. I speculate that this linguistic constraint negatively affects our ability to sense and receive into ourselves the presence of the other. As Thomas Berry (1988) would say, perhaps we have become quite autistic.

I would like to share the following story of my own to illustrate this notion of moral autism. At a conference not too long ago, I heard a deeply inspiring keynote speech on the theme of the caring curriculum. A thundering applause indicated that the audience was very much moved by the speech. The whole audience was then divided into small groups of ten or so to engage in dialogue about what we had heard. Thus, I found myself with a small group of strangers. It turned out, from the round of self-introductions which followed that in our group were many participants from abroad who had to struggle with 
their English. Amongst those who were native speakers of English, there was a woman who exuded an air of self-confidence and leadership, and she initiated the discussions, which was much appreciated. However, when she began to speak, it was evident that she was so involved in her own self-expression that she was oblivious of our international participants having difficulties in keeping up with her. She went on for some time, discoursing in the best academic style. Finally, a man sitting next to me interrupted her with a sensitive apology, suggesting that perhaps we should check with our international participants to see if they were doing alright. They were not.

What my story illustrates for me is that our capacity for empathy and, therefore, moral caring is very much compromised because of our habitual egocentric mode. It is as though we each walk around with a thick blanket around our head, thus impaired to see, feel, and hear how others are. Likewise, with a blanket around our head, others cannot perceive us well. We go around cacooned in a blanket of our own thoughts and desires, schemes and projects.

\section{Decentering the ego-self}

The question that shall exercise me now is how we may go about decentering egocentricism and radically (in the original sense of getting to the root of) expanding care-consciousness. How can we become expansively caring to the point of being able to see the whole of humanity and all the sentient beings as moral subjects to whom one is prepared to bestow an equal caring as to oneself? I am compelled to ask this question by my perception that the current world situation of rampant ethnic wars, the rise of senseless crimes against innocent people, and world-wide famine and environmental degradation, desperately demands of us to radically expand our caring capacity. As I indicated earlier, I am doubtful that we could be radically caring on the model of the self-other dichotomy. As long as self-regard is pitted against other-regard, chances are that the former wins over, or at least greatly impedes, the latter, which suggests to me that it is this dichotomy itself that has to be overcome. Yet, I admit that the task seems totally daunting, given that most of us are firmly entrenched in the view that the self-other separation is part of our inherent and invariant psychic structure. I challenge this belief. Indeed, in my stating that such a notion is a belief, I have already challenged it. If it is a belief, it can always be revised and replaced, notwithstanding the difficulties of getting around our grammar.

The moment I "forget" to make the distinction between my garbage and someone else's, I would simply pick up the garbage that happens to lie in front of me in the same way that I would pick up the garbage that I dropped. Similarly, the moment my hand just reaches out, even without my conscious knowing, to support a staggering stranger who happens to be near me in the street, it is as though in that brief moment of reaction, I did not distinguish the other from the self for that motion of sudden reaching out for support is the same spontaneous, proprioceptive gesture of grasping for support if I myself were to stagger unsteadily.

In both of these examples, my caring "behaviour" is predicated upon a prior sense of intrinsic relatedness between an individual as a physical body and other bodies or things that surround it. I pick up my garbage and take care of it because I do not think of it as a foreign matter that I should reject or ignore. I 
pick up someone else's garbage littering the street because I do not perceive the street as a foreign site unrelated to me but as a site where my self is "happening" in dialogical interaction with it. Thus, the garbage on the street, too, is not unrelated to me. The second example I gave is even more telling and would support my claim that at the physical level we are actually far more self-otherrelated than we assume ourselves to be. If I were not somehow unconsciously, but in the bodily way, already attuned to another person near me, I would not have responded appropriately, as if I were in tune with that person. It is as if my proprioception extends beyond my body to other bodies around me. Could we not think of moral caring as a kind of moral proprioception?

Consider another example. In our culture, we are typically not intrinsically related to the land, by which I mean we do not care for the land as we would care for our own selves. Under the rubric of development and profit, land is exploited and commodified. Thus, for us, land is not a moral subject but a commercial object. It would take a tremendous effort on our part to overcome the existing understanding of the land and to recover a decper sense of intrinsic relatedness to the point of wanting to extend the deepest caring to the land. Facing an extensive deforestation world-wide, projected to be catastrophic, recovering such sense of deep intrinsic relatedness or continuity with the land is not an exotic option but may well be our best survival strategy.

In trying to get a sense of what something looks like, there is nothing quite like seeing an actual full-blown example of it. What would a truly decentered subject, capable of self-other continuity, be like? And what practices may cultivate such a subject? In the next section, I raise the example of Buddhism as a theory and practice of radical decentering. I use this example, not because I think that Buddhism is the only tradition capable of teaching us decentering and overcoming the self-other dichotomy but because, first, this is the tradition that I am most familiar with and have studied; and second, this tradition rigorously articulates the epistemological conditions behind caring consciousness and details the practices of the non-dual, caring consciousness.

\section{The Buddhist Care-consciousness}

Changing our metaphysics changes the way we apprehend and, therefore, relate to the world. Or, I should say, after Putman (1990), any particular metaphysics is a prescription as to how we ought to say, think, perceive, and so on. Buddhism as a metaphysical system is a critique of what in the West has come to referred to as a "Cartesian" substantialist metaphysics wherein "things" are understood to have inherent, atomistic, and, therefore, independent self-identities (Kalupahana, 1987; Varela, Thompson, \& Rosch, 1991). In this view, "things" may undergo various changes, but their core essence, which defines their self-identity, remains unchanged. For instance, a person is said to be the same person, despite constant changes throughout her lifetime, because the essence of the person-the authentic self, the soul, the mind, the substance, or whatever-remains the same. Likewise for other entities in the phenomenal world. But, says the Buddhist, this belief in a world of essence, substance, or inherent, self-same properties is illusory for even just by logically thinking through the matter, one may realize that the belief in the self-constituted, selfsufficient nature of things is not defensible and does not cohere with experience upon close inspection. How so? 
The argument runs roughly like this: Nothing in our phenomenal world has an immanently self-constituted, self-defining nature because each and every thing is constituted by a plethora of other elements. In other words, what defines a thing is not itself but something else. Thus, there is not a thing in the phenomenal world which does not depend on other things for its self-definition. Thich Nhat Hanh (1991, pp. 95-96), the Vietnamese Zen monk and peace activist, has written a lucid essay titled Interbeing on the absence of self-nature of all things, and I shall quote an extensively abridged passage as an illustration of this argument:

If you are a poet, you will see clearly that there is a cloud floating in this sheet of paper. Without a cloud, there will be no rain; without rain, the trees cannot grow; and without trees, we cannot make paper. ... If we look into this paper even more deeply, we can see the sunshine in it ... we can see the logger . . . wheat. ... The logger's father and mother are in it, too. ... Looking even more deeply, we can see ourselves in this sheet of paper, too. This is not difficult to see, because when we look at a sheet of paper, it is part of our perception. ... Everything co-exists with this sheet of paper. ... This sheet of paper is, because everything else is.

As I noted earlier, Thich Nhat Hanh has coined the term "interbeing" to connote the Dependent Co-arising (paticca-samuppada) of all phenomena, including the self and the object.

From the perspective of Dependent Co-arising, the self and the other as designators for independent entities are illusory, for, "[m]utually conditioned, everything subsists in relationship and knows no independent self-existence"; a self is but a "stream of being, a stream of consciousness," and is like a fire, "[co-igniting] with what it perceives and on which it acts." 16 This description of the self, not as a solid and enduring entity or substance but as a fluid, dynamic process, is not just a figure of speech but is based on experience or phenomenal observation, the attainment of which is the work of the practice of Buddhist mindfulness (Satipatthana), popularly known as meditation. Again, in this short essay, I can only briefly touch on the topic.

All forms of discursive practices are helpful in orienting us towards certain views and compel us to entertain certain "pictures" of the world. However, they may still be a step short of helping us to embody these pictures and to translate them into experience, for which we may need a more direct way of working with our consciousness. The mindfulness practice, more popularly known as meditation, is one such way. It aims not at giving us a "picture" of, or an argument for, a way of being, but a direct taste, feel, and insight of it. In particular, it aims at enabling the practitioner to psychologically deconstruct the usual habitual way of seeing and relating to the world in terms of the subjectobject dichotomy. This deconstruction takes the form of what I would call "temporalization of all objects," including the self, thereby rendering them as fluid, dynamic, co-emergent events or arisings. As the meditator becomes more and more refined at maintaining close attention to his or her stream of consciousness, he or she may begin to notice "the temporal nature of perception prior to pattern recognition, before stimuli are built up into recognizable percepts or ordinary experience."17 Ultimately, the mediator might experience something like the following, as Engler explains: 
When this total moment-to-moment "coming to be and passing away" is experienced, there is a profound understanding of the radical impermanence (anicca) of all events. Not only do I no longer perceive any durable "objects," but even the processes of thinking, feeling, perceiving, and sensing themselves come to be and pass away without remainder. In this experience of perpetual and discontinuous change, such notions as a solid body, a durable perceptual object, an internal representation, or even a fixed point of observation no longer appear tenable. I come to understand the lack of any intrinsic durability anywhere; I become aware of the selflessness (anatta) of mind, body, external objects and internal representations. Not only does everything change all the time; there are no "things" which change. ${ }^{18}$

When the self-other duality is psychologically deconstructed as through mindfulness practice, the usual categorical distinctions that separate one entity from another are seen to be human constructs, which is to say that they are not a matter of representations of reality, albeit all the same significant and, if chosen appropriately, useful. This temporal, nonsubstantialistic apperception of the world and the self may become, through cultivation, the foundational layer of the meditator's experience upon which the more mundane, substantialistic layers of apperception are built. Thus, it is not as though the meditators, once achieving the nonsubstantialist apperception, would be unable to interact with the world as functionally egoic individuals, unable to deploy the grammar of subject-object duality. But such functional individuality is deeply informed and modified by the insubstantialistic view of the self and the world. The best way I can picture this mode of consciousness is as dynamic layering. The attainer of such multiplex consciousness would appear as a functional egoic individual but is not limited to this and, hence, his or her participation in the egoic individuality would be subjunctive and ironic.

What difference would attaining the view and experience of Dependent Co-arising, ontonomy, or nonduality, make for our moral life and practice of caring? There are different conceptions of what it is to be moral and practice caring. The Buddhist conception, based on the realization of the subject-object or self-other inseparableness and continuity, is bound to be different from ones that take the duality of the self and the other as an inevitable and fundamental given and accordingly work out a deontological prescription or a consequentialist calculus or even a contractarian framework for moral caring. Leaving the detail of comparison to the interested reader, I will just comment on moral caring based on nonduality: to a person who has or is inclined to overcome the categorical separation of the subject and object, caring is not a moral imperative, an obligation that one has to perform towards the world. Nor will caring have consequential objectives, such as happiness, peace, higher quality of living, and the like, although these are likely attained without being aimed at. Caring is simply a natural, inevitable expression of the enlightened mind-heart which perceives itself to be continuous with the world. Loy says this of the bodhisattva, one who is committed to the ideal and practice of promoting wellbeing for all sentient forms (1996, p. 126): "The career of the bodhisattva is helping others, not because one ought to do, for the bodhisattva is not bound by dogma or [conventional] morality, but because one is the situation, and through oneself that situation draws forth a response to meet its needs." 


\section{Education, non-dualistically}

With the previous exemplification of the mindfulness practice, I do not wish to leave an impression with the reader that I am prescribing such practice in schools. While such practice can indeed be incorporated into curricula with many beneficial results, I believe that my notion of ontonomy through decentering the ego subjectivity is both more radical and less specific, if applied to our educational practice. It is more radical in the sense that it addresses the fundamental aims and character of education; and it is less specific in the sense that the practice is not confined to a skill or subject but permeates all school subjects and activities. I shall elaborate my points a little.

The culture of our education is steeped in fortification of the self, as can be attested by the prevailing educational objectives of personal empowerment, autonomy, control, self-esteem, mastery, and competitiveness. As I remarked earlier, even the current renewed emphasis on co-operation and community cannot dispel the foundational egoic orientation of our education and appears to sit uneasily with the latter, if not actually to be part of the same. As long as these are taken instrumentally in the service of the individual self, there is no real change to the traditional individualistic framework of education. In this framework, education with all its material conditions - such as school buildings, equipment, textbooks, and teachers-is the means and resource to producing individuals of certain qualifications. But if we shift our educational paradigm to that of ontonomy, then education is not a means to anything but simply a practice and enjoyment of ontonomy itself. It has no aims other than itself-namely, harmonious ways of being in the world, and to this end our learning and teaching take ourselves deeper and deeper into the art of caring. We study the forest, animals, cities, gardens, history, literature, the people, and so on in order to be better connected to them and, thus, be able to take care of them more skillfully and artfully. To be well-educated individuals in this educational paradigm is to be lovers and nurturers of the world.

Now, my reader might comment that it is not as though students do not already study these subjects and topics, and so the question that may be directed to me is just how differently these are handled in the ontonomical education. Not all ways of studying a subject would have the same result. I can study a forest with an intent of destroying it or of saving it. "Forms" of intention, even if not made known explicitly, guide the content and the manner of study. Or conversely, if we are perspicacious thinkers, we may be able to discern the intention from the content and manner of study. Following this line of observation, I ask what the intention looks like behind the curriculum that focuses mostly on the disciplinary subjects but not enough on the students except when they prove to be difficult or challenged learners. By not bringing the students' subjectivity into intimate relationship with the objective field (the study), the intent of the study becomes, by omission, absence of caring towards what is studied for caring includes the knowing, empathic subject. If I were to study the water cycle in the manner of acquiring a pile of information, will I come away with a profound appreciation, caring, and reverence towards water? In the ontonomic practice of education, however, it will not be just the subject matter that will have to be studied but the knowing subject's (student's) deepening

Paideusis 
relationship to it. The objective of such study would be the student's moving from a tenuous, limited, or extrinsic relationship with the object to a deeper and intrinsic one. Such a mode of study will involve the self's exploration and articulation of its perception, emotion, intention, and beliefs while these are engaged with the subject matter. Thus, for example, the teacher teaching in this mode will not be concerned just with whether the students have learnt given facts or mastered certain skills but how differently they come to perceive, feel, think, and act as a result of or inspired by their engagement with their study.

If studying can be an activity of transfusing the self with the object of study as well as with an environment which includes both the people we study with and the physical setting in which we study, then nonduality or continuity of the self and the other could be realized. Such, I argue, is the source of moral caring. But when students are inducted into the perception and practice of externalizing and disconnecting the self from what, why, how, where, and with whom they study, the result is a radically diminished capacity for caring.

\section{Notes}

1 The Independent Commission on Population and Quality of Life defines carrying capacity as "the maximal sustainable load that humankind can impose on the environment before it loses its capacity to support human activity" (Pintasilgo et al., 1996, p. 97).

2 In the same report, I learned that one-third of the world population is without rudimentary sanitation. Ibid., p. 21.

3 According to the same report, in 1994 there were some 1.3 billion people in absolute poverty, and the gap between the richest 20 percent and the poorest 20 percent is widening.

${ }^{4}$ In my opinion, a major step in this direction is to construe economics as part of ecology. Such a step has been taken with Daly and Cobb's $(1989,1994)$ publication of For the Common Good: Redirecting the Economy towards Community, the Environment, and a Sustainable Future.

5 Positioning of this boundary varies greatly from individual to individual, and culture to culture. In the Hobbesian worldview, the boundary may end at the individual self. In some other worldviews-for example, the First Nations' and the Classical Chinese, the boundary may extend far into future generations and over the whole of Nature.

6 A certain amount of guardedness with respect to strangers is only reasonable. A stranger is a stranger precisely because one does not know how they will act. By "xenophobia" here, however, I mean something more insidious. It is the human tendency to separate what belongs to one's own kind from what does not and, moreover, to devalue and even oppress the latter. This tendency plays out intrapsychically, too, and we call it repression.

7 In "answering" this question, I am deeply influenced by the Buddhist psychology and existential psychotherapy. See Loy (1996).

8 This notion of the enaction of mutual perception by equal consociates figures centrally in both Taylor (1994) and Habermas (1994) in their respective defences of the "politics of recognition."

${ }^{9}$ Contemporary postmodern discourse is preoccupied with the problems of subjectivity and self-identity. As Nancy put it: 
The inaugurating decisions of contemporary thought whether they took place under the sign of a break with metaphysics and its poorly pitched questions, under the sign of a "deconstruction" of this metaphysics, under that of a transference of the thinking Being to the thinking of life, or of the Other, or of language, etc. have all involved putting subjectivity on trial. A widespread discourse of recent date proclaimed the subject's simple liquidation. $(1991$, p. 5).

The legitimacy of the notion of an authorial, autonomous self is hotly debated while feminist critics are deeply worried about the political consequences of the postmodern deconstruction of subjectivity and self-identity. I do not wish to get mired in these debates since my purpose here lies elsewhere. But I acknowledge that the postmodern problematization of the atomistic, autonomous, and selfpresencing subject makes it less daunting for me to advance a conception of self that departs from the traditional atomistic subjectivity.

10 The prevailing Western model of moral education is still heavily influenced by the Kantian moral thought (carried through Piaget and Kohlberg in our century) which focuses on the development of autonomous self (Scheewind, 1998) which, I suggest, should be seen as a progressive abstraction and isolation of the self from its environing elements. Thus abstracted, the self then stands sovereign over and above these elements, exerting control.

11 In other words, no individual advantage, no co-operation. If so, there is no inherent committment to co-operation. It is a thin conception of cooperation, but I think it is the most we can expect from individualism.

12 William James came to a similar understanding, according to Wilshire (1992, p. 208): "For James, the self includes all that I can call mine, and a startling vista opens. Others whose opinions of me matter to me are $m y$ others and form my "social self." As appropriated by me, their images of me belong in my body, says James!"

13 A passage from Wittgenstein's Tractatus (1961): "5.6-The limits of my language mean the limits of my world."

14 For instance, Cummings and Oldham (1998) recommend mindfulness training into classroom practice and claim, based on preliminary research, that such practice develops students' cognitive and emotional abilities.

15 Actually, my description here of ontonomic learning and teaching should be no stranger to the reader. The basic ideas here have been voiced by the giants of our educational ancestors, Whitehead and Dewey. Here I quote a passage from Whitehead (1929, p. 3): "By utilizing an idea, I mean relating it to that stream, compounded of sense perception, feelings, hopes, desires, and of mental activities adjusting thought to thought, which forms our life." Dewey (1938), too, was explicating the same idea with his notion of the "experiential continuum" wherein the objective conditions (the curriculum) and the subjective conditions (the student) interact and integrate. Dewey insisted that the teacher be ever mindful of what is happening in the students' experiential continuum and discern opportunities for educational growth.

\footnotetext{
16 Macy, 1991, p. 110.

${ }^{17}$ Engler, 1986, p. 42.

18 Ibid., p. 43.
} 


\section{References}

Books.

Berry, T. (1988). The dream of the earth. San Francisco: Sierra Club

Blum, L. (1994). Moral perception and particularity. Cambridge: Cambridge University Press.

Cummings P. \& Oldham, L. (1998). "Mindfulness in the classroom." http://www.doubleclickd.com/Articles/mindclass.html Mindfulness in the Classroom article.

Daly, H. \& Cobb, J. (1994). For the common good: Redirecting the economy toward community, the environment, and a sustainable future. Boston: Beacon.

Dewey, J. (1938). Experience and education. New York: Macmillan Publishing Company.

Engler, J. (1986). "Therapeutic aims in psychotherapy and meditation: Developmental stages in the representation of self." In K. Wilber, J. Engler, \& D.P. Brown (Eds.), Transformations of Consciousness. Boston: Shambhala.

Habermas, J. (1994). "Struggles for recognition in the democratic constitutional state." In A. Gutman (Ed.), Multiculturalism. Princeton: Princeton University Press.

Hanh, Thich Nhat (1991). Peace is every step: The path of mindfulness in everyday life. New York: Bantam Books.

Kalupahana, D. (1987. The principles of Buddhist psychology. Albany, NY: State University of New York Press.

Loy, D. (1996). Lack and transcendence: The problem of death and life in psychotherapy, existentialism, and Buddhism. Atlantic Highlands, NJ: Humanities Press.

Macy, J. (1991). Mutual causality in Buddhism and general systems theory: The dharma of natural systems. Albany, NY: State University of New York Press.

Nancy, J. (1991). “Introduction." In Cadava, E., Connor, P., \& Nancy, J. (Eds.), Who comes after the subject? (pp. 1-8). London: Routledge.

Orr, D. (1994). Earth in mind: On education, environment, and the human prospect. Washington: Island Press.

Panikkar, R. (1991). "A nonary of priorities." In J. Ogilvy (Ed.), Revisioning philosophy (235-246). Albany, NY: State University of New York Press.

Pintasilgo, M. et al. (1996). Caring for the future: Report of the Independent Commission on Population and Quality of Life. Oxford: Oxford University Press.

Putnam, H. (1990). Realism with a human face. Cambridge: Harvard University Press.

Schneewind, J.B. (1998). The invention of autonomy: A history of modern moral philosophy. Cambridge: Cambridge University Press.

Taylor, C. (1994). "The politics of recognition." In A. Gutman (Ed.), Multiculturalism. Princeton, NJ: Princeton University Press.

Tu, W. (1994). "Embodying the universe: A note on Confucian selfrealization." In R.T. Ames, W. Dissanayake and T.P. Kasulis (Eds.), Self as person in Asian theory and practice (pp. 177-186). Albany, NY: State University of New York Press.

12(2), (Spring)1999 
Usher, R. \& Edwards, R. (1994). Postmodernism and education. London: Routledge.

Varela, F.J., E. Thompson \& E. Rosch. (1991). The embodied mind: Cognitive science and human experience. Cambridge, MA: The MIT Press.

Whitehead, A.N. (1929). The aims of education. New York: Free Press.

Wilshire, B. (1992). "Resistance to tolerance and pluralism in worldcommunity: Otherness as contamination." In J. Ogilvy (Ed.), Revisioning philosophy (pp. 203-216). Albany, NY: State University of New York Press.

Wittgenstein, L. (1961). Tractatus logico-philosophicus. London: Routledge \& Kegan Paul. 